\title{
EDU-AGRIKULTURAL DI CENGKARENG
}

\author{
Abiel Kristianto ${ }^{1)}$, Tatang H. Pangestu ${ }^{2)}$ \\ 1)Program Studi S1 Arsitektur, Fakultas Teknik, Universitas Tarumanagara, abielkristianto@gmail.com \\ 2) Program Studi S1 Arsitektur, Fakultas Teknik, Universitas Tarumanagara, tatang_pangestu@hotmail.com
}

\begin{abstract}
Abstrak
Perkembangan teknologi internet semakin canggih membuat penyebaran informasi semakin cepat hal ini membuat orang mudah mengetahui banyak hal, salah satunya adalah bahaya nya "industrial food system" bagi iklim maupun kesehatan manusia. Industrial food menggunakan bahan bakar fosil yang pasca penggunaannya berbahaya bagi atmosphere kita serta kurangnya gizi pada makanan industrial food. hal ini menyadarkan masyarakat khususnya millenials sehingga lebih banyak mengkonsumsi makanan organik ketimbang baby boomers. Populasi tertingi di jaman ini adalah millenials, dapat disimpulkan demand makanan organik akan semakin meningkat. Fenomena ini membuka peluang bagi para petani dan entrepreneur untuk berbisnis, namun kota semakin berkembang dan lahan untuk bercocok tanam semakin berkurang juga. oleh karena itu perlu adanya teknologi di bidang agrikultur seperti teknologi vertical farming, pencahayaan buatan, nutrisi, dan sebagainya untuk mengatasi perluasan wilayah kota tanpa menggangu daya produksi pangan. dengan demikian diperlukan wadah untuk mengedukasi petani/masyarakat yang mayoritasnya millenials untuk menangapi peluang tersebut. baik secara bisnis model maupun teknologi seputar agrikultural. Edu-Agrikultural di Cengkareng merupakan wadah bagi para petani dan para entrepreneur generasi millenial untuk belajar seputar perihal agrikultur baik secara produksi, teknolgi/riset, hingga pembelajaran mengenai bisnis model agrikultur itu sendiri. dengan pendekatan memperhatikan karakteristik dan tingkah laku millenial untuk kasus ini adalah cara belajar. sehinga menghasilkan program ruang yang sesuai dengan karakteristik dan tingkah laku millenials. Hadirnya proyek ini diharapkan kota dapat terus berkembang tanpa harus mengganggu daya produksi pangan, urban farmers dapat memaksimalkan hasil produksinya di lahan yang terbatas. para entrepreneur dapat memaksimalkan potensi pasar dibidang ini, serta diharapkan dapat membudayakan "real food" system yang baik bagi lingkungan, petani, serta konsumen.
\end{abstract}

Kata kunci: Agrikultural; Edukasi; Millennial; teknologi

\begin{abstract}
The development of increasingly sophisticated internet technology makes the spread of information faster, this makes it easy for people to know many things, one of which is the danger of the "industrial food system" for climate and human health. Industrial food uses fossil fuels that are postuse harmful to our atmosphere and lack nutrition in industrial food. this made people aware, especially millenials, of consuming more organic food than baby boomers. The highest population in this era is millenials, it can be concluded that the demand for organic food will increase. This phenomenon opens opportunities for farmers and entrepreneurs to do business, but cities are growing and land for farming is also decreasing. Edu-Agriculture in Cengkareng is a place for farmers and millennial generation entrepreneurs to learn about agriculture both in production, technology / research, and learning about the business of the agricultural model itself. with the approach of paying attention to millennial characteristics and behavior for this case is a way of learning. so that it produces space programs that are in accordance with the characteristics and behavior of millenials. The presence of this project is expected that cities can continue to develop without having to disrupt the power of food production, urban farmers can maximize their production on limited land. entrepreneurs can maximize market potential in this field, and are expected to cultivate a "real food" system that is good for the environment, farmers and consumers.
\end{abstract}

Keywords: Agriculture; Education; Millennial; Urban farmer 


\section{PENDAHULUAN}

\section{Latar Belakang}

Sustainable Development Goals (disingkat SDGs), yaitu agenda pembangunan berkelanjutan dunia hingga 2030 yang terdiri dari 17 poin, seharusnya dipenuhi secara berurutan karena telah diurutkan berdasarkan skala prioritas; dari hal yang paling mendasar hingga hal yang bersifat opsional, menurut Marc Buckley. Agrikultur, Makanan, dan Air Bersih merupakan salah satu hal yang paling mendasar di SDGs karena merupakan pemenuhan dari poin nomor 2 dalam SDGs yaitu Pemberantasan Kelaparan (Zero Hunger).

Fenomena peningkatan kebutuhan makanan yang bersifat real-food yang sedang marak akhir-akhir ini, tentunya tidak terlepas dari tren hidup sehat yang dibawa oleh generasi millennial. Generasi millennial, yang memiliki tingkat pengetahuan dan kepedulian yang lebih tinggi terhadap kesehatan, hadir dengan dukungan keras terhadap real food system dan menolak industrial food system. Hal ini terlihat dari kecenderungan millennial yang lebih menyukai makanan organik dibandingkan non organik.

Sekalipun fenomena ini sebenarnya baik untuk keberlangsungan hidup manusia dan realfood system sebenarnya sangat baik untuk lingkungan, konsumen, dan produsen, namun kebutuhan akan real-food dan pemberlakuan real-food system ini terbentur dengan ketersediaan lahan pertanian yang dibutuhkan untuk produksi yang semakin menurun. Semakin terbatasnya ketersediaan lahan untuk digarap ini tentunya berkaitan dengan industrialisasi desa-desa yang mulai menjadi kota.

Dengan demikian, diperlukan teknologi di bidang agrikultur seperti vertical farming dan teknologi agrikultur lainnya untuk menjadi solusi terhadap ketimpangan pemenuhan kebutuhan pangan masyarakat dengan ketersediaan lahan yang ada. Modernisasi perlu dilakukan di Indonesia yang masih menganut sistem yang cenderung konvensional untuk meningkatkan efektivitas dan efisiensi lahan.

Edu-Agrikultural hadir sebagai wadah edukasi yang mempersiapkan para pelaku di bidang agrikultur, agar kebutuhan pangan masyarakat terhadap real-food dapat terpenuhi.

\section{Permasalahan Perencanaan dan Perancangan}

Fokus utama permasalahan dalam perencanaan dan perancangan yang diangkat pada proyek ini antara lain:

\section{Perencanaan}

- Bagaimana menghasilkan program edukasi yang kontekstual dengan kebutuhan generasi millenials.

\section{Perancangan}

- $\quad$ siteplanning: bagaimana bangunan dapat saling terkoneksi dengan nyaman secara pencapaian maupun bukaan bangunan dengan bangunan sekitarnya

- building: bagaimana program dapat saling terintegrasi antar masing-masing kegiatannya dengan mudah.

\section{Ruang Lingkup}

Peneliti memfokuskan edu-agrikultural di bidang tanaman pangan saja baik edukasi produksi, teknologi dan bisnis model Tujuan Proyek.

\section{KAJIAN LITERATUR}

\section{Tipe, Perilaku, dan Nilai Kesejamanan (Millennial)}

Tipe: Menurut Kamus Bahasa Inggris Oxford, mendeskripsikan tipe sebagai "bentuk umum, struktur, atau karakter yang membedakan jenis, kelompok, atau class tertentu dari makhluk atau benda", sebagai "pola atau model setelah sesuatu dibuat", dan sebagai "sosok atau gambar sesuatu; representasi; gambar atau imitasi." 
Perilaku: Menurut Skinner, seperti yang dikutip oleh Notoatmodjo (2003), merumuskan bahwa perilaku merupakan respon atau reaksi seseorang terhadap stimulus atau rangsangan dari luar. Oleh karena perilaku ini terjadi melalui proses adanya stimulus terhadap organisme, dan kemudian organisme tersebut merespons, maka teori Skinner ini disebut teori "S-O-R" atau Stimulus - Organisme - Respon.

Arsitektur: Menurut Amos Rappoport mengatakan bahwa arsitektur merupakan ruang lokasi hidup manusia yang bukan hanya sekadar fisik, tapi juga menyangkut pranatapranata kebiasaan dasar. Pranata-pranata tersebut antara lain: tata atur kebiasaan dan sosial masyarakat yang turut diwadahi dan mempengaruhi arsitektur.

Kesejamanan: merupakan stimulus contohnya seperti perkembangan teknologi, sosial budaya, ekonomi, politik dan sebagainya.(abiel,2019)

Rekapitulasi: (Kesejamanan/stimulus $\rightarrow$ perilaku ) $\rightarrow$ type/kategori/kelompok $\rightarrow$ architecture. Hubungan antara arsitektur-tipe-perilaku-nilai kesejamanan antara lain kesejamanan merupakan stimulus dan behavior berbentuk dari respon terhadap stimulus, type dapat mengkategorikan kesejamanan-behaviour, dan type dapat membantu arsitektur dalam melihat kebiasaan/perilaku pada jamannya.

\section{Cengkareng Edu-Agricultural}

Edukasi: Pengertian Edukasi atau disebut juga dengan pendidikan merupakan segala upaya yang direncanakan untuk mempengaruhi orang lain baik individu, kelompok, atau masyarakat sehingga mereka melakukan apa yang diharapkan oleh pelaku pendidikan (Notoadmojo, 2003). Edukasi merupakan proses belajar dari tidak tahu tentang nilai kesehatan menjadi tahu (Suliha, 2002).

Agriculutral: Menurut Cambridge dictionary Agricultural adalah used for farming or relating to farming

Agriculture: Mennurut Meriam Webster Agriculture adalah the science, art, or practice of cultivating the soil, producing crops, and raising livestock and in varying degrees the preparation and marketing of the resulting products

Rekapitulasi: Edu-Agricultural artinya: segala upaya yang direncanakan untuk mempengaruhi individu atau kelompok mengenai kegiatan-kegiatan yang berkaitan dengan agrikultur

\section{Cara belajar millenial}

Menurut Diana Oblinger, milenial memiliki cara belajar yang berbeda dari generasi sebelumnya diantaranya adalah teamwork, experiential activities,structure, and use technology dalam jurnalnya understanding a new students

Menurut meriam Webster, Experiential relating to, derived from, or providing experience

Menurut Cambridge Dictionary experience adalah (the process of getting) knowledge or skill from doing, seeing, or feeling things

Rekapitulasi Cara belajar millenial lebih ke arah observasi, melakukan, merasakan, dan melihat secara langsung/ dengan melakukan trial and error, diskusi dua arah, kerja sama, serta penggunaan teknologi

\section{DISKUSI DAN HASIL}

\section{Penjelasan Proyek}

Edu-Agrikultur di Cengkareng merupakan wadah bagi para petani, ahli, dan pengusaha sebagai tempat edukasi seputar agrikultur baik secara metode produksi, teknologi, \& bisnis dengan program yang berfokus kepada cara belajar millenials menurut Diana Oblinger diantaranya teamwork, experiential activities,structure, and use technology dalam jurnalnya understanding a new students. Edu-Agrikultural di Cengkareng memiliki program seperti 
workshop, seminar, diskusi, riset, eksibisi teknologi agrikultur, hingga kegiatan vertical farming, urban gardening, real food district, dan real food market.

\section{Visi}

Kota dapat terus berkembang tanpa harus mengurangi daya produksi pangan Misi

Memperkenalkan dan mewadahi para petani dalam belajar akan teknologi agrikultur salah satunya vertical farming, mewadahi para ahli untuk mengembangkan teknologi agrikultur, dan memperkenalkan bisnis model seputar agrikultur.

\section{Programmatik}

\section{Edu-Agricultural}

Merupakan program edukasi seputar dunia agrikultur, edukasi, mengenai perkembangan teknologi, metode, sampai bisnis model dari agrikultur itu sendiri. Kegiatannya diantara lain belajar melalui sharing antar komunitas, sharing antar entrepreneur, agrikultur, seminar/talkshow dari para ahli, praktik langsung pembedahan teknologi agrikultur itu sendiri, sehingga dapat menghadirkan wadah edukasi yang kontekstual dengan generasi millenial

Kebutuhan ruang:

- R.seminar/talkshow

- R.mentoring

- Gallery pameran

- Workshop

- Penunjang

\section{Vertical Farming}

Merupakan program untuk memenuhi kebutuhan demand sayur-sayuran, serta sebagai kegiatan praktek langsung dari pembinaan edu-agrikulural. Kegiatannya antara lain, melakukan penyemaian bibit, menanam bibit, menuai hasil tanam. Hadirnya program ini agar dapat memenuhi demand bahan baku "real food" pada lahan yang sempit

Kebutuhan ruang

- R.penyemaian

- R.aeroponik

- R.simpan hasil tuaian

- Pasar

- penunjang

\section{Real Food District}

Merupakan program yang menyajikan makanan-makanan dengan real food system, dimana bahan baku dari bahan organic yang diambil langsung dari hasil panen vertical farming, kegiatannya makan, minum istirahat. Tujuan dari program ini adalah agar real food system yang memiliki keuntungan bagi petani,konsumen, dan lingkungan ini semakin terkenal di kalangan masyarakat:

kebutuhan ruang:

- Ruang mkanan dan minum

- Ruang persiapan dan penyajian

- Gallery

- penunjang

\section{Urban Gardening}

Program yang dilahirkan dari kawasan tersebut dimana adanya fenomena kios tanaman hias dan kurangnya ruang public pada kawasan cengkareng, kegiatannya, bercocok tanam, 
istirahat, panen. Hadirnya program ini agar memiliki ruang publik yang memiliki program yang kontekstual dengan lingkungannya.

Kebutuhan ruang:

- ruang makan dan minu

- gallery

- penunjang

\section{Metode Perancangan}

Metode perancangan difokuskan untuk mengintegrasikan program-program yang telah dihasilkan dengan menandakan setiap program yang saling memiliki hubungan. Seperti matriks di bawah ini dimana kotak hitam menandakan adanya relasi dengan program tersebut. Dan hasilnya program urban gardening/ruang publik (nomor 20) memiliki keterkaitan antara setiap program yang ada

\section{Tapak}

Lokasi tapak terpilih adalah: Cengkareng yang berada di Cikini, Jakarta Barat karena telah memenuhi kriteria diantara lainnya:

- Dekat dengan urban farmer

khususnya yang masih menggunakan teknologi konvensional. Agar kawasan urban farmer tersebut dapat maju dengan adanya edukasi seputar agricultural.

- Akses mudah, agar memudahkan orang-orang yang ada di kota maupun luar kota untuk dapat menghadiri kegiatan edu-agrikultural ini.

- Dekat dengan permukiman, agar program "real food district" dapat efektif. karena dengan dekat demikian pemkiman bias mendapatkan pilihan makanan-makanan yang sehat setiap harinya, karena jangkauannya yang mudah.

\section{Proses Pembentukan Massa}

Proses pembentukan massa menggunakan pendekatan dengan memperhatikan lingkungan sekitarnya agar menghasilkan gubahan massa yang kontekstual lingkunan sekitarnya.

\section{KESIMPULAN DAN SARAN}

Edukasi dapat meningkatkan pengetahuan masyarakat, dengan adanya pengetahuan setiap individu semakin percaya diri dalam melakukan sesuatu demikian juga dengan EduAgrikultural di Cengkareng ini diharapkan meningkatkan pengetahuan akan teknologi,metode, serta bisnis model dengan program pembelajaran yang berasal dari pendekatan karakteristik dan perilaku millenial antara lain experiential,collaborative, dan sebagainya. Dengan demikian program Edu-Agrikultural di Cengkareng ini dapat memfasilitasi generasi millenials sekarang ini. Selain itu juga hadirnya Edu-Agrikultural akan melahirkan sumber daya manusia yang kompeten dalam penggunaan teknologi seperti vertical farming dan teknologi agrikultur lainnya sehingga kota tetap dapat berkembang tanpa mengganggu daya produksi pangan. Dengan demikian juga kebutuhan pangan untuk "real food" yang memiliki benefit baik pada petani,konsumen, dan lingkungan ini juga dapat terpenuhi.

Sebaiknya program edu-agrikultural ini dapat diberlangsungkan dan diperbanyak untuk mempersiapkan sumber daya manusia dibidang agrikultur. agar Indonesia memiliki sumberdaya manusia yang berkompeten di bidang agrikultur sehingga kebutuhan pangan masyarakat terhadap real food dapat terpenuhi. 


\section{REFERENSI}

Erickson, T.J. (2012). The Millennials. London: RSA.

Fourhooks. (2015,). The Generation Guide- MIllenials, Gen X, Y, Z and baby boomers.

MIX MarComm. (2018). Millennials. NewYork: Fantasious.

Neufert, P. dan Ernst. (1970). Architects' Data 3. Oxford: Blackwell Science.

https://smartcity.jakarta.go.id/maps (Di akses Januari 6, 2019)

https://en.oxforddictionaries.com/definition/type (Di akses Januari 8, 2019)

https://www.seeker.com/rise-in-veganism-more-young-people-care-where-their-food-comes-

from-1978795333.html (Di akses Januari 8, 2019)

https://medium.com/studiotmd/gen-y-millennials-in- architecture-476e9839321b (di akses Januari 10, 2019)

https://er.educause.edu/articles/2003/1/boomers-genxers-and-millennials-understanding-

the-new-students (di akses Januari 15,2019)

http://sdgs.bappenas.go.id/ (di akses Januari 15, 2019)

https://www.google.com/maps (di akses Januari 16, 2019)

http://sdgs.bappenas.go.id/kota-dan-pemukiman-yang-berkelanjutan/ (di akses Januari 16, 2019)

http://sdgs.bappenas.go.id/pekerjaan-layak-dan-pertumbuhan-ekonomi/ (di akses Januari 16, 2019,)

http://sdgs.bappenas.go.id/kota-dan-pemukiman-yang-berkelanjutan/ (di akses Januari 16, 2019)

http://alvara-strategic.com/generasi-millennial-indonesia- (di akses Februari 10,2019)

https://er.educause.edu/articles/2003/1/boomers-genxers-and-millennials-understandingthe-new-students 